Riga, Latvia, March 12-13, 2021

\title{
INNOVATIVE APPROACHES TO IMPROVING PRIMARY SCHOOL STUDENT'S HEALTH STATUS
}

\author{
Olena Yelizarova ${ }^{1}$ \\ Natalia Duiba ${ }^{2}$
}

\section{DOI: https://doi.org/10.30525/978-9934-26-050-6-15}

Increasing the prevalence of Noncommunicable Diseases and Mental Health Disorders (NMH) which increase the mortality and disability of adults in most countries of the world are challenging for the scientific community to look for new ways of prevention using innovative multidisciplinary methods [1-2]. Risk factors of NMH are personal behaviour or lifestyle, environmental exposure, hereditary characteristic, anxiety disorders, depression. Preventive measures are usually aimed at modifiable risk factors such as lifestyle and mental health. The most promising ways of primary prevention of $\mathrm{NMH}$ is the correction of the behaviour of primary school children. This period of ontogenesis is characterized by accelerating mental development and the formation of purposeful behaviour against the background of morpho functional adjustment and growth [3]. The researches show that in Ukraine most first-grade students have average and low level of health. During schooling, the percentage of healthy children decreases by $11 \%$ (from $16.1 \%$ in 1st grades to $5.2 \%$ in the 11th grades) [4-5]. At this presentation, we will consider Innovation Health Promotion Programs in Primary Schools (HPPS), which are used to correct functional abnormalities in the body of primary school children and form a habit to a healthy lifestyle.

HPPS are the effective multiply-discipline programs are aimed at correcting both mental health and physical activity. The relationship between physical and psychological well-being has long been a paradigm for the implementation of health saving technologies in the educational process. Mental health disorders are known to worse physical health, the deterioration of which in turn leads to psychological disorders (Figure 1).

This vicious circle is reducing adaptation in children, increasing the risk of developing chronic diseases in childhood and NMH in adulthood. The circle can be broken by introducing innovative methods to improve mental health and increase physical activity in primary school. There are techniques in the arsenal of school psychologists that can significantly improve both the mental and physical health of students. In our opinion, there are two promising areas both Arts therapy and the Theory of Planned Behavior (TPB).

\footnotetext{
${ }^{1}$ SI «O.M. Marzieiev Institute for Public Health, NAMSU», Ukraine

${ }^{2}$ Brovary School № 9, Ukraine
} 


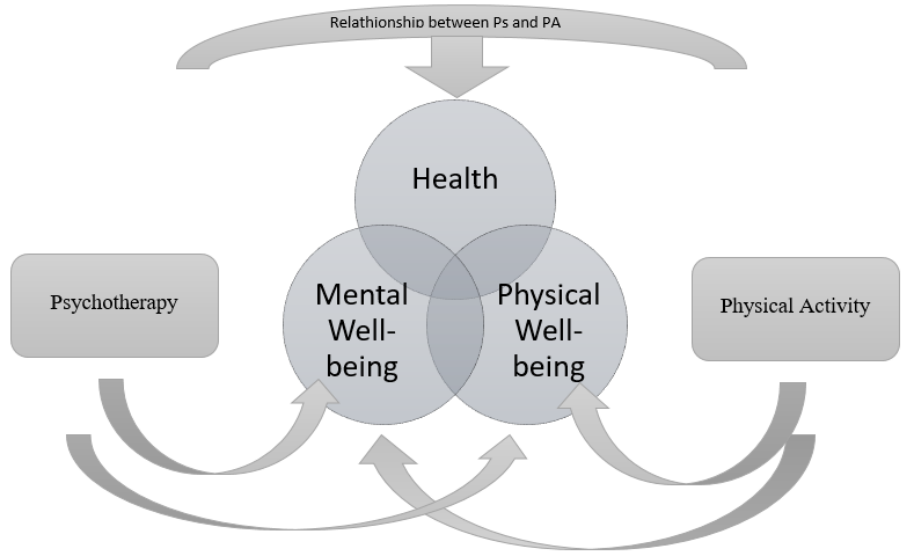

\section{Figure 1. Model of the relationship between physical and psychological well-being}

Arts therapy is the most progressive method that allows psychotherapy with art, music, drama and dance. These are well-known methods that are still widely used in hospitals for the treatment of both mental health disorders and in preparation for surgery and rehabilitation. In addition, art therapy is successfully implemented in educational institutions in order to correct behavioral factors, reduce anxiety and form a habit to a healthy lifestyle. Arts therapy helps to express verbal constructions in a non-verbal way to establish and consolidate communicative connections. Creativity helps to sublimate feelings and this makes it possible to correct destructive inclinations. As a result of the therapy, a balance is achieved between both mental and physical health. These approaches are aimed at restoring homeostasis, reducing anxiety, increasing physical activity and consolidating healthy habits in the future.

There are also interventions at the schools by using the tools of the Theory of Planned Behavior [6]. TPB is part of the Behavioral Economic and is an innovative approach used by economics and marketing earlier. These models typically integrate insights from psychology, neuroscience and microeconomic theory and whether of individual or group behaviour. Interventions in schools from 4 months to 1 year conducted using these techniques showed a significant reduction of anxiety, increased well-being and improved fitness in study participants [7-9], which indicated the prospects for their further use. 
It has been shown that TPB is particularly suitable for predicting physical activity behaviour [10]. In France, the two-year program The Great Live and Move Challenge (GLMC) was developed and implemented on the basis of the TPB, aimed at increasing the physical activity of children aged 7-11 [11], which is expected to be completed in two years. The goal of the GLMC intervention is to increase the proportion of children who reach the 60 -minute MVPA per day recommended by the World Health Organization by $15 \%$. There is also a randomized cluster study using behavioural and physical activity change methods in Finland [12].

There were significant positive changes in terms of physical fitness and mental health status after the intervention HPPS and we see the obvious benefits of such measures. First, children are happy to participate in such programs, which affects their self-esteem and psychological status. Second, children experience a healthy lifestyle and remember its benefits, which may be an incentive to start exercising again in the future. Third, the advantage of school interventions is the involvement in physical activity of children from different walks of life, which leads to access to new methods of physical education for children from low-income families.

Thus, the implantation of multiply-discipline Innovation Health Promotion Programs in Primary Schools today is the most promising area, which allows increasing the adaptation of children to the learning process and to life situations.

\section{References:}

1. Noncommunicable diseases country profiles (2018). Geneva: World Health Organization. Retrieved from: https://www.who.int/nmh/publications/ncd-profiles2018/en/ (accessed 11 March 2021).

2. Patel V., Saxena S., Lund C., Thornicroft G., Baingana F., Bolton P., Chisholm D., Collins P. Y., Cooper J. L., Eaton J., Herrman H., Herzallah M. M., Huang Y., Jordans M., Kleinman A., Medina-Mora M. E., Morgan E., Niaz U., Omigbodun, O., Prince M., ... UnÜtzer J. (2018). The Lancet Commission on global mental health and sustainable development, vol. 392, pp. 1553-1598. doi: 10.1016/S0140-6736(18)31612-X

3. Armitage C.J., \& Sprigg C.A. (2010). The roles of behavioral and implementation intentions in changing physical activity in young children with low socioeconomic status. Journal of sport \& exercise psychology, vol. 32, no. 3, pp. 359-376. Retrieved from: doi: 10.1123/jsep.32.3.359

4. Mykhno L.S. (2015) Otsinka deiakykh pokaznykiv fizychnoho zdorovia pershoklasnykiv [Assessment of some indicators of physical health of first-graders]. Slobozhanskiy Science and Sports Visnik, vol. 45, no. 1, pp. 91-94. doi: 10.15391/snsv.2015-1.017

5. Harkusha S.V. (2013). Suchasni tendentsii u stani zdorovia ditei i molodi v umovakh navchannia. [Current trends in the health of children and youth in the 
educational environment]. Pedagogy, psychology and medical and biological problems of physical education and sports, no. 10, pp. 7-11. Retrieved from: http://nbuv.gov.ua/UJRN/PPMB_2013_10_4 (accessed 11 March 2021).

6. Glanz K., Rimer B.K., Viswanath K. (ed.) (2008). Theory, research, and practice in health behavior and health education. Health behavior and health education: theory, research, and practice. Fourth. San Francisco: John Wiley \& Sons; pp. 24-40. Retrieved from: https://www.researchgate.net/publication/288927435_Health_Behavior_and_ Health_Education_Theory_Research_and_Practice (accessed 11 March 2021).

7. Zimmerman F.J. (2009). Using behavioral economics to promote physical activity. Preventive medicine, vol. 49, no. 4, pp. 289-291. doi: 10.1016/ j.ypmed.2009.07.008

8. Louise Bush P., Laberge S., Laforest S. (2010). Physical activity promotion among underserved adolescents: «make it fun, easy, and popular». Health promotion practice, vol. 11, Suppl. 3, pp. 79-87. doi: 10.1177/1524839908329117 (accessed 11 March 2021).

9. Bonhauser M., Fernandez G., Püschel K., Yañez F., Montero J., Thompson B., Coronado G. (2005). Improving physical fitness and emotional well-being in adolescents of low socioeconomic status in Chile: results of a school-based controlled trial. Health promotion international, vol. 20, no. 2, pp. 113-122. doi: 10.1093/heapro/dah603 (accessed 11 March 2021).

10. McEachan R., Conner M., Taylor N.J., Lawton R.J. (2011). Prospective prediction of health-related behaviours with the Theory of Planned Behaviour: a metaanalysis. Health Psychology Review, vol. 5, no. 2, pp. 97-144. doi: 10.1080/ 17437199.2010.521684 (accessed 11 March 2021).

11. Cousson-Gélie F., Carayol M., Fregeac B. (2019). The «great live and move challenge»: a program to promote physical activity among children aged 7-11 years. Design and implementation of a cluster-randomized controlled trial. (electronic journal) BMC Public Health, vol. 19, 367. doi: 10.1186/s12889-019-6648-x (accessed 11 March 2021).

12. Hankonen N., Heino M. T., Araujo-Soares V., Sniehotta F. F., Sund R., Vasankari T., Absetz P., Borodulin K., Uutela A., Lintunen T., Haukkala A. (2016). 'Let's Move It' - a school-based multilevel intervention to increase physical activity and reduce sedentary behaviour among older adolescents in vocational secondary schools: a study protocol for a cluster-randomised trial. BMC public health, vol. 16, 451. Retrieved from: https://www.ncbi.nlm.nih.gov/pmc/articles/PMC4882860/ (accessed 11 March 2021). 